Copyright (C) 2014 by Academic Publishing House Researcher

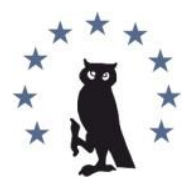

Published in the Russian Federation

European Researcher

Has been issued since 2010.

ISSN 2219-8229

E-ISSN 2224-0136

Vol. 85, No. 10-2, pp. 1865-1873, 2014

DOI: $10.13187 /$ er.2014.85.1865

www.erjournal.ru

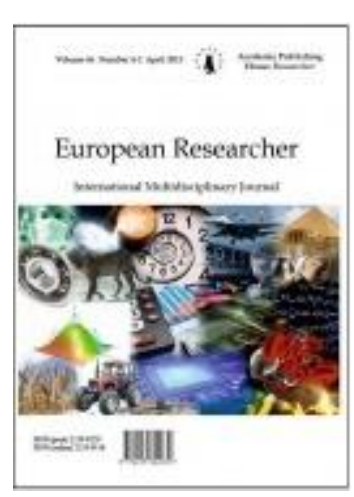

Psychological sciences

Психологические науки

UDC 159.9

\title{
An Approach on the Quality of Life of Community Health Agents in Mental Health Area
}

1 Ulysses Rodrigues de Castro

2 Antonio José Pacheco Palha

${ }^{3}$ Nelson Rocha de Oliveira

4 José Carlos Amado Martins

1 Instituto de Saúde Mental, Brazil

FHDF, Granja Riacho Fundo, s/n, Riacho Fundo I, DF. CEP: 71800-001

E-mail: ulycastro@bol.com.br

2 (Professor)

Rua do Carvalho, 109 - 40 EA - CEP: 4150-192 - Porto - Portugal

E-mail: palha@gmail.com

3 SIGA Ârea Especial No 2, Brazil

Setor Leste - Gama-DF. CEP: 72460-00o

E-mail: nelsonoliveira@gmail.com

${ }^{4}$ Rua 5 de Outubro, Av. Bissaya Barreto, Apartado 7001. CEP: 3046-851. COIMBRA, Portugal

E-mail:jmartins@esenfc.pt

\begin{abstract}
The quality of life discussion is increasing because it starts to bring the conditions and lifestyle as topics. This concern is also being observed in the workplace, and the work life quality is an important issue in the bioethics of protection view. So, this article aims to understand the quality of life of mental health professionals, specifically the community health agents of the Federal District in Brazil. Methods: A survey called WHOQOL-10o from the World Health Organization was used to describe the sociodemographic characteristics and the quality of life of the community health agents. Collected data were analyzed by SPSS 19.0 computer program. Results: Results indicated that the quality of life revealed by the five domains of Whoqol -100 is located around $57 \%$. Considering the aspects evaluated, we realized that no one reached greater percentage than or equal to $80 \%$ value. Some sociodemographic variables are associated with significant differences between the means in some domains of Whoqol - 100. In Social and Environmental Affairs domains, the averages between men and women were significantly different. The Socioeconomic Level of Community Health Agents was also associated with significant
\end{abstract}


differences in the level of independence. Conclusions: We observed that the quality of life for those workers passes before anything for its humanization.

Keywords: primary care; quality of life; mental professional; community health agents.

\section{Introduction}

The contemporary discussion of quality of life is comprehensive because it starts to bring the conditions and lifestyle as topics, besides the issues of symptom control, reduced mortality, increased life expectancy, some common points in the first bioethical thoughts about this subject. The current definition of quality of life adds other perspectives without unlinking the first.

The Group for Research and Study of Physical Activity and Quality of Life comprises quality of life as the individual's perception of their position in the context of culture and value systems in which they live and in relation to their goals, expectations, standards and concerns until the ethical and policy dimension ${ }^{[1]}$.

Nowadays discussions of quality of life approach biomedical, psychological, socioeconomic and general aspects. The general approach consists of the quality of life for a multidimensional perspective. In the words of Almeida \& Gutierrez ${ }^{[1]}$ quality of life "presents a complex organization and dynamics of its components, differing from person to person according to their environment/context and even between two people engaged in a similar context. Characteristics such as values, intelligence, interests are important".

The socioeconomic approach takes social indicators as a reference. Government data of management, economic indicators with inflation index, among others are understood as its implications for the quality of life of a particular population.

Medical approaches in the opinion of Almeida \& Gutierrez ${ }^{[1]}$ are comprehensive and therefore is common conceptualization of quality of life expand. In the medical literature the quality of life has been associated with several meanings as health and social functioning.

Silva ${ }^{[2]}$ observes that human work should be carried out in conditions that contribute to the full development of the worker and his life, respecting their physical and mental integrity. However, work activities, in different degrees of intensity, can often cause deleterious health effects, leaving aside the question of physical and mental integrity. In such cases, the work can take an ambiguous role in the life of the individual, and may be the cause of suffering or even illness for many people.

According to Fleck [3], health has been defined by the World Health Organization (WHO), in 1946 , as "a state of complete physical, mental and social wellbeing and not merely the absence of disease". However, the concern with improving health has intensified in the mid 70s, where it was observed that health was not merely the absence of disease.

The concept of quality of life began to be linked to the measurement of indicators of health from this decade. This change is associated with at least six strands which converge to the improvement of the concept of quality of life, such as: studies of epidemiological base about happiness and well-being; pursuit of social indicators; lack of objective outcome measures in health; positive psychology; customer satisfaction; humanization movement of medicina [4].

The old discussion followed the ethical biomedical clinic paradigm which understands the issue of quality of life guided only by medical issues. With the paradigm shift the medical institutes began to consider the human dimension linked to the people thougths with regard to their dreams, what they expect from life and how it is done, or not, in a social and cultural context.

After these changes, the next stage was the adoption of initiatives to measure quality of life. There is a significant amount of meters of quality of life used in scientific researches. During the 90s there were some initiatives that helped the development of a more holistic view about the quality of life. The WHOQOL is the name of the group of quality of life developed by WHO to address issues involving this topic. Later, the group's name became the name of the questionnaire developed to measure quality of life. This questionary works with four major themes: Physical, psychological, social relationships and environment. At this same time several studies that aimed to develop metrics for measuring quality of life were done ${ }^{[3]}$.

These studies were done because during the late 2oth century, with the fall of Berlin wall, the focus of world attention is no longer polarized contest between capitalism and socialism. Thus, the attention began to turn to voices that have echoed in societies, but they were not heard. People and groups who were violated for reasons of social order began to organize themselves and their claims 
began to be heard. Those claims were in vast majority clamored for citizenship or for social justice and equity. At their heart they brought more than a social issue, they brought the human yearning for a better life [5].

Therefore the World Health Organization took forward an international collaborative project that resulted in the WHOQOL. This questionnaire has defined quality of life as "the individual's perception of their position in life in the context of culture and value systems in which they live in relation to their goals, expectations, standards and concerns" [5]. The fact that both the process creation of WHOQOL as the translation into Portuguese, have the presence of health professionals in the group of participants is important in measuring quality of life for professionals in the health field.

During the 70s, the term Quality of Work Life (QWL) was seen as a concern for the health of the individual in view of the results of their work tasks. In Brazil, during the same period, the newly created Sanitarian movement already discussed the implications of this dehumanized model that only favored the business sector ${ }^{[6]}$.

The concept of QWL has since continued to be developed and improved by bringing perspectives, pathways and newer approaches. Discussion on the conditions and working environment remained and were being updated. Further discussions as the impression that workers had about the work itself, ie, how they understood the meaning of their own practice and their role as a worker, began to emerge.

Today, the concept of QWL is more holistic, as it undertakes, steadily, subjective and objective studies and discussions of work and workers. Because of this QVT is often used as an indicator of personal experiences in the organization and the level of employee satisfaction. The quality of life at work stems from a need for efficiency in service delivery. Goal is achieved, first, with the optimization of human resources, ie, issues of organizational climate directly affect the quality of services provided. We notice as well, that this proposal to make it more comprehensive discussion, the quality of life becomes to be linked to occupational stress, which opens up the range of futher discussion. In this sense, the evaluation initiatives to mesure stress and quality of life become better understood, however, in proportion, more complex to be measured [6].

This reality is also observed in a group of professionals that was instituted in Brazil, more specifically in the state of Ceará, working with the issue of patient care, but where they live. These workers are called Community Health Agents, and differ from other health professional, such as nurses, because they perform their work within their own communities, visiting patients in their homes, and only then, leading to the diagnoses within the hospitals. From these assumptions of quality of life, thinking about this kind of professionals that are also related to occupational stress, this study aimed to measure the quality of life of some community health agents who work in the mental health field.

\section{Materials and methods}

Description of the sample of participants

The sample consisted of 97 community health agents mostly women $(78.4 \%)$. The age of almost half of the group falls in the age group 30-39 years (40.2\%), married (51\%), have 1-3 children (60.8 \%) and has a medium socioeconomic level (57.7 \%) or low (34 \%). The group is divided between those who develop basic work (55.7\%) or medium (41.2 \%). The vast majority of agents work 40 hours per week (97.9\%) in the morning/afternoon shift (96.9\%).

\section{Procedures}

Assessing the quality of life of community health agents was performed by the instrument response of World Health Organization, the WHOQOL - 100, a validated version in Brazil, consisting 100 questions, grouped into six domains: physical, psychological, level of idependência, social relationships, environment and spirituality/personal beliefs. Each domain consists of facets, with a total of 24 facets, which are composed of four whestion. Besides the 24 facets, the instrument consists of a twenty-fifth facect which consists of general questions about quality of life. The response values were converted to percentage from o to 100, with higher values are indicative of better quality of life.

The questionnaire was administered in December 2012, in a private room, on the premises of the health centers. The project was approved by the ethics committee of FEPECS/SE/ DF under 
No. 643/11, adopted on 02/15/2012. The 97 community health agents who agreed to participate signed an informed consent, anonymity and confidentiality of information is guaranteed. In order to ensure the confidentiality of the study, were not disclosed the names of family health units that were part of this research.

The statistical treatment of the data was performed using the statistical package SPSS version 19.0. Analysis for the differences in mean QWL in terms of demographic and socioeconomic variables, the Tukey test was used.

\section{Results}

\section{Quality of Life ( WHOQOL - 100)}

Domains and Facets of Quality of Life

According to the results obtained, it was possible to ascertain the quality of life of the Community Health Agents active in teams of family health in mental health area. The results of WHOQOL percentages were transformed to allow a comparison between their domains and facets. Figure 1 shows the average percentage observed in the trial Physical, Psychological, Level of Independence, Social Relations, Environment and Self- rating of quality of life domains.

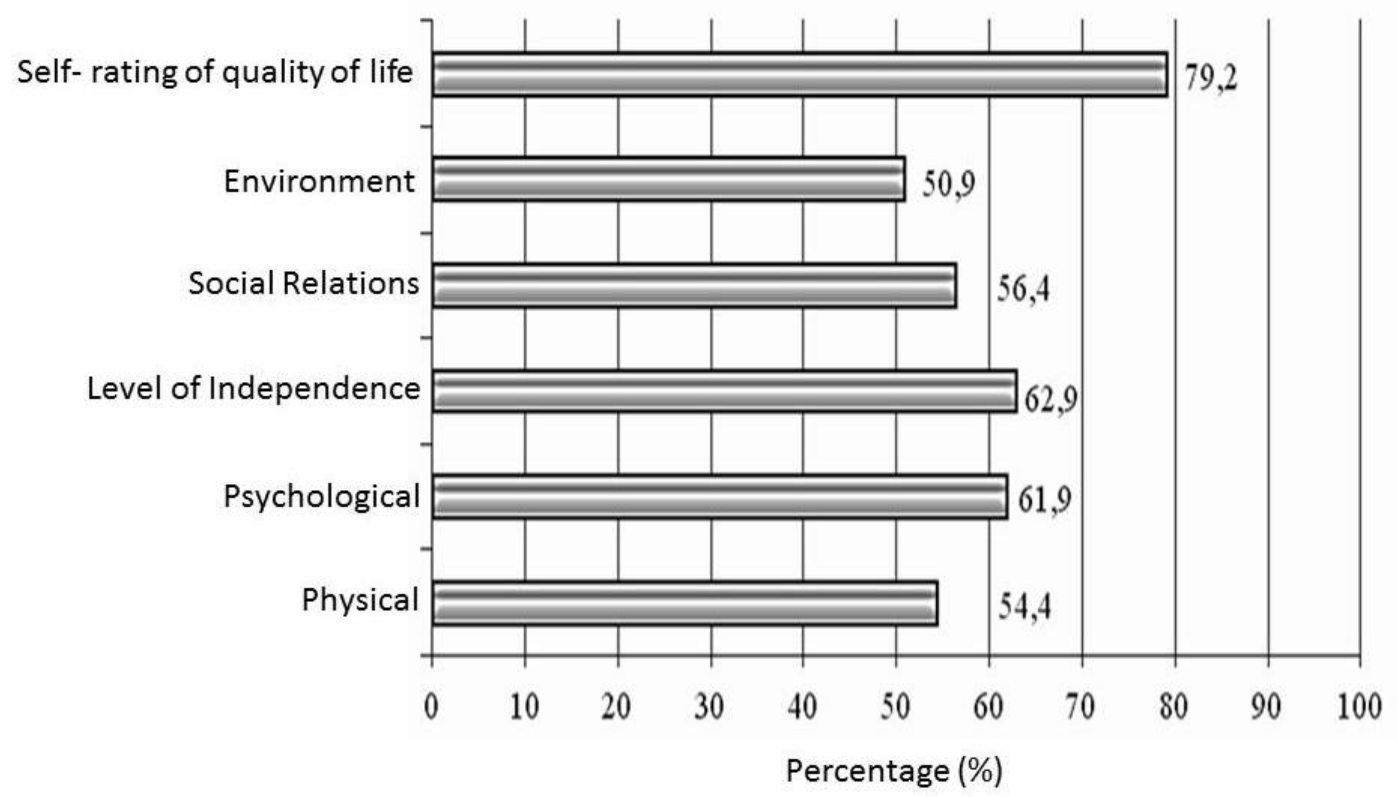

Figure 1. Judgement average percentage of each domain of the WHOQOL instrument. Federal District, Brazil. 2014

The average percentage trials indicate that CHA evaluated the areas of Quality of Life (QWL) from $50 \%$ to $63 \%$. It is noteworthy that the self- assessment of QWL was superior to any area considered. The domain that received lower review was Environment that includes the facets: financial resources; Health and Social Care (availability and quality); Environment at Home; Participation in and opportunities for recreation/leisure; Physical Environment (pollution/noise / traffic / climate); Physical Security and Protection; and Transportation. This review is the average range of the trial responses. It was not observed a significant discrepancy between the percentage values of the other fields.

Table 1 reports the average percentage judgments observed in every facet of the WHOQOL. Averages are presented in decreasing order of magnitude. The average of the trials ranged from $24.2 \%$ to $79.2 \%$. 
Table 1: Trial mean percentage and standard deviation (SD) of facets. Federal District, Brazil. 2014

\begin{tabular}{|c|c|c|}
\hline Facet & Average & $\overline{\mathrm{SD}}$ \\
\hline Spirituality / religion / personal beliefs & 79,2 & 18,08 \\
\hline Ability to work & 73,7 & 17,97 \\
\hline Self-esteem & 67,2 & 17,32 \\
\hline Positive feelings & 65,5 & 16,06 \\
\hline Sleep and rest & 64,1 & 27,11 \\
\hline Thinking, learning, memory and concentration & 62,6 & 15,47 \\
\hline Body image and appearance & 62,2 & 19,08 \\
\hline Home environment & 62,1 & 15,93 \\
\hline Quality of life from the point of reported view & 62,0 & 16,12 \\
\hline Social Support & 58,9 & 16,89 \\
\hline Personal Relationships & 58,4 & 12,27 \\
\hline $\begin{array}{l}\text { Opportunities for acquiring new information and } \\
\text { skills }\end{array}$ & 57,3 & 13,91 \\
\hline Physical security and protection & 54,4 & 14,58 \\
\hline Pain and discomfort & 53,4 & 17,02 \\
\hline Energy and fatigue & 52,4 & 18,03 \\
\hline Sexual activity & 51,7 & 16,62 \\
\hline $\begin{array}{c}\text { Participation in and opportunities for recreation } \\
\text { / leisure }\end{array}$ & 51,7 & 18,3 \\
\hline Mobility & 51,4 & 11,13 \\
\hline Activities of daily living & 50,5 & 10,18 \\
\hline Financial Resources & 49,9 & 7,01 \\
\hline Negative feelings & 47,8 & 21,92 \\
\hline $\begin{array}{l}\text { Physical environment (pollution/noise/traffic/ } \\
\text { climate) }\end{array}$ & 47,7 & 10,72 \\
\hline Transportation & 44,5 & 12,16 \\
\hline Health and social care: accessibility and quality & 39,5 & 18,17 \\
\hline Dependence on medication or treatments & 24,2 & 24,5 \\
\hline
\end{tabular}

The facets that received the lowest average judgments were health care and social care: accessibility and quality and dependence on medication or treatments (Table 1). Only 8\% of the veneers had an average in the range of $70 \%$ to $79 \% ; 28 \%$ had a mean $60 \%$ to $69 \%$; $40 \%$ had an average of $50 \%$ to $59 \%$; and $16 \%$ were between $40 \%$ to $49 \%$.

An analysis of the frequency distribution of averages shows that $3 \%$ is in the range from 1.82 to $1.97 ; 32 \%$ to the range 2.1 to $2.99 ; 58 \%$ to the range 3.02 to 3.92 ; and $7 \%$ to the range 4.0 to 4.23. This means that the range of responses scale assessment center ("neither satisfied nor dissatisfied" or "somewhat" or "neither good nor bad", or "medium" or "sometimes") prevailed between evaluations of CHA. The extremes of the scale ("nothing/very dissatisfied/very bad" and "extremely/very satisfied/very good") were hardly mentioned.

\section{Areas in terms of socioeconomic and demographic factors}

It was not possible to observe statistically significant differences between the mean scores of the domains of quality of life when compared between the variables: age, marital status, job, education, number of dependents, and socioeconomic status.

With regard to the areas by gender, table 2 shows the means and standard deviations of rates observed in each area depending on the participant sex. The table indicates that all judgments of women are higher than ratings made by men. One-way ANOVA revealed that there are significant differences between the means on the basis of sex in domain IV - Social Relations, and domain V - 
Environment. There was a marginally significant effect of Sex in Domain II - Psychological [F $(1,94)=3.801, p=0.054]$. Subsequent tests (Tukey) between the means indicated that female CHA had higher averages than men in those three domains.

Table 2: Distribution of the results of the domains by gender. Brazil, 2014

\begin{tabular}{ccccccc}
\hline \hline Sex & $\begin{array}{c}\text { Physical } \\
\text { Domain }\end{array}$ & $\begin{array}{c}\text { Psychological } \\
\text { Domain }\end{array}$ & $\begin{array}{c}\text { IL } \\
\text { Domain }\end{array}$ & $\begin{array}{c}\text { SR } \\
\text { Domain }\end{array}$ & $\begin{array}{c}\text { Enviromnent } \\
\text { Domain }\end{array}$ \\
\hline Average & MALE & 50,1 & 56,7 & 61,9 & 50,2 & 47,3 \\
SD & MALE & 16,4 & 15,4 & 7,0 & 9,4 & 8,8 \\
Average & FEMALE & 55,6 & 63,6 & 63,5 & 58,2 & 52,0 \\
SD & FEMALE & 16,0 & 13,8 & 8,8 & 11,3 & 8,6 \\
\hline \hline
\end{tabular}

Legend: SD = standard deviation, IL = Level of Independence, SR = Social Relations.

Means and standard deviations of the ratios as a function of socioeconomic level of the CHA are presented in table 3. One-way ANOVA revealed significant differences between means according to the socioeconomic level in domain III - Level of Independence. Subsequent tests of Tukey between the means indicated that CHA with low socioeconomic level nave level of Independence significantly higher of the CHA with medium socioeconomic level.

Table 3: Distribution of the results of the domains by socioeconomic level. Brazil, 2014

\begin{tabular}{ccccccc}
\hline \hline & SL & $\begin{array}{c}\text { Physical } \\
\text { Domain }\end{array}$ & $\begin{array}{c}\text { Psychological } \\
\text { Domain }\end{array}$ & $\begin{array}{c}\text { IL } \\
\text { Domain }\end{array}$ & $\begin{array}{c}\text { SR } \\
\text { Domain }\end{array}$ & $\begin{array}{c}\text { Enviromnent } \\
\text { Domain }\end{array}$ \\
\hline Average & VLSL & 60,2 & 63,9 & 61,3 & 54,2 & 47,5 \\
SD & VLSL & 12,5 & 8,6 & 4,4 & 10,1 & 9,1 \\
Average & LSL & 56,2 & 63,5 & 66,1 & 58,8 & 51,6 \\
SD & LSL & 17,7 & 14,2 & 8,5 & 12,2 & 9,9 \\
Average & MSL & 52,5 & 60,7 & 61,1 & 55,2 & 50,9 \\
SD & MSL & 15,4 & 15,4 & 9,1 & 11,1 & 8,2 \\
\hline \hline
\end{tabular}

Legend: SL = socioeconomic level, SD = standard deviation, VLSL = very low socioeconomic level, $\mathrm{LSL}=$ low socioeconomic level, MSL = medium socioeconomic level, IL = Level of Independence, $\mathrm{SR}=$ Social Relations.

\section{Discussion}

The CHA judged, on average, that the quality of life revealed by the five domains is located around $57 \%$. This percentage draws attention compared with the Self-Assessment of Quality of Life that is over $20 \%$ higher $(79.2 \%)$. Whereas facets evaluated, we realized that no one reached values higher than or equal to $80 \%$. Most was evaluated in the range of $50 \%$ to $67.2 \%$, and six are below $50 \%$.

Impaired quality of life of health workers can directly influence the provision of services. This can affect the dynamics of care, bringing damages to the patients care.

It was found greater satisfaction with the level of independence domain of quality of life of CHA assessed. Thus, mobility, daily life activities, dependence on medication or treatment and work capacity facets were aspects that provide higher levels of perceived quality of life of studied workers. Similar results were found by Fernandes et al. [7], working with nurses in family health teams of the 27 municipalities of Minas Gerais Macro-region of Health, in Brazil, where observed higher averages for level of independence and social relationships, using the responses of the evaluation instrument WHOQOL - 100.

Lopes \& Macedo ${ }^{[8]}$, in a study conducted with nurses from 11 units of family health, in Vitória da Conquista, Bahia, Brazil, observed, using the WHOQOL Breaf, that the highest score among the domains assessed were physical, followed by the psychic domain. The psychic domain, in our study, also had the highest scores, indicating that this aspect, connected to psychological issue, has great relevance to $\mathrm{CHA}$ with regard to quality of life. The psychological issue involves the dimensions of human life, ie, aspects like how to enjoy life, live well, with self satisfaction and satisfaction the other, without the presence of negative feelings. Vasconcellos \& Costa Val [9] also 
found that the psychological domain was presented the third highest score when evaluating the Community Health Agents in Lagoa Santa, Minas Gerais, in Brazil, using the WHOQOL Breaf.

Thus, subjective reactions and experiences of human beings are indicators involved in psychological approach. Almeida \& Gutierrez ${ }^{[1]}$ claim that this approach depends on direct experience of the person whose life is being assessed and indicate how people perceive their own lives, happiness or satisfaction. The autors says that fact of psychological approaches consider quality of life only as an aspect within a person, disregarding the environmental context in which it operates, is the main limitation of this line of thought ${ }^{[1]}$.

As regards the "state of health and quality of life related to health" variables are disposed through a linear progression with respect to proximity to the individual, the more proximal (symptoms) to the distal (opportunities). According Patrick [10], assessment of quality of life is inseparable from personal or sociocultural context. In this sense, to mesure quality of life can be it is necessary to see all factos that involves the particular pearson.

The environment domain, where they are inserted the facets: financial resorces, health and social care, home environment, participation in recreation and leisure activities, factors related to pollution, noise, traffic, safety and transportation, showed the lowest percentage indicating that have less influency as regards the quality of work life. Factors such as availability of human resources, the organization of the work process and the recognition of the good way to take care of the assisted population, may be one of the factor that the environment domain presented the lowest percentage. Similar results were also found by Lopes \& Macedo ${ }^{[8]}$.

Mendonca \& Oliveira [11], in work done of the quality of life of primary care workers of Amparo, São Paulo, Brazil, observed that physical, psychological, socias relations and the environment presented scores $68.58 ; 63.31 ; 66.24$ and 57.42 , respectively. Ursine et al. ${ }^{[12]}$ also conducted a work with community health agents in the Family Health Strategy of the brasilian government, in Londrina, Paraná, to investigate the working conditions and quality of life of workers and found that the physical domain obtained the average score of 74 , the psychological obtained a mean score of 71.5 and the lowest mean score was found in the environment field, that also corroborates the findings of the current work. It's important to call attencion to the fact of the CHA work in their own community. This fact can give them mor facility on mobility, on transportation, and they may be more confortable working with people that they already know for a long time. So the enviromnent may be favorable for their actvities.

According Pascoal \& Tamayo [13], the study of quality of life can be based on organizational stressors (work enviromnent stimuli that require adaptive responses by the employee and that exceed their coping ability), in the individual responses (psychological, physiological and behavioral responses issued by individual by work factors that exceed their coping skill), or in several variables in the stressor response process. Thus, re-educative measures can be articulated in order to provide better quality of working life in health and mental health, to also provide improved services to beneficiaries.

An analysis of the mean values obtained for each WHOQOL question showed that the CHA tended to opt for the medium scale of answers ("neither satisfied nor dissatisfied" or "somewhat" or "neither good nor bad", or "medium" or "sometimes"). As this chosen workers are in a low level of work, they often show fear to say what they realy thinks about some subject at work. They have fear that something could happen with their jobs if they say something that could desagree with their boss, even when the survey is done preserving the secrecy of identity. So, they mostly prefer to chose answers that may not affect them.

Some sociodemographic variables are associated with significant differences between the means in some domains. In Social Relacions and Environmental Domains, averages between men and women were significantly different. The Socioeconomic Level of CHA was also associated with significant differences in the level of independence. The other sociodemographic characteristics did not produce significant differences.

About the results is important to note that the health worker read in a care process paradox: life and death. Moreover, the nurse professional or community health agent, work on a human nature process that can occur both in the perspective of promotion, as the prevention and / or recovery of health ${ }^{[14]}$. Trevisan et al. ${ }^{[15]}$ consider that this type of work requires an intense human 
relationship, ie, which is intrinsic inter - relationship and bond. Then appear as productive action and social interaction simultaneously.

Research indicates that the reality in Brazil has shown that there is a partial or incomplete understanding about the quality of life of health professionals work in practice. According Miranda [16], the welfare referential is linked to quality performance focused on people. Sometimes meritorious, or simply managerial actions, ignore quality of work life on companies policies and processes or in repair risks aspects in working condition.

In this sense, promoting quality of life, according Gonsalves ${ }^{[17]}$, would mean promoting the quality of work and employment having as a starting point safety assurance in career and employment, ensuring employability, income, social protection and workers' rights; maintenance and promotion of health and well - being of workers through health care and exposure to hazards at work and work organization more appropriate and effective; developing skills and competencies through training, training, career development; reconciliation of life inside and outside work by reducing or adequacy of extension of working time, the flexibility of time devoted to work and the creation of social support structures.

\section{Conclusion}

The quality of work life passes before anything for its humanization. It's important to understand that, whether being boss or employee, needs quality of working life, not just for reasons that attach directly to work - as their production, goals and their challenges - but also by the relation of this work with a social context - such as compliance with legislation and to the recognition that society gives to work. Therefore the measurement of quality of life should always keep up with current issues or the most modern understanding of what will be evaluated about work quality of life.

Social participation, the management model to be adopted by governments and representatives of the people and the set of actions developed by professionals in the health field are extremely important for establishing quality of life for health professionals and also to improve health conditions of the Brazilian population. CHA are professionals who interact directly with the population, their desires, perspectives, and also sorrows and difficulties. Understand how the quality of life of these professionals is an important measure for both regard to the personal touch as iin what refers to the sphere of society in general.

There are only few studies on quality of work life for health care agents. In this sense, there is a need for greater efforts to understand how these professionals are considered, and how is the job of each one, to the betterment of their condittion of work and the community which they are inserted.

In this sense, it`s important to look for some principle that could help these health professionals. The bioethics in understood as a legitimate and efficient tool for critical analysis of the morality of public policies in the area of health and for the decision making. According to Schramm \& Kottow ${ }^{[18]}$ the principle of protection meets the requirements of ethics in public health and allows moral justification and analysis of public policies, by requiring clear identification of objectives and authors involved in the implementation. So, the bioethics of protection aplication facing these health professionals, the community health agents, can ensure better professional development inside and outside of your work environment.

\section{References:}

1. ALMEIDA, M.A.B., GUTIERREZ, G.L. (2010). Quality of Life: contemporary discussions . In: Quality of Life: Evolution of Concepts and Practices of the XXI Century . 1st ed. Campinas, 151-160.

2. SILVA, M.E. (2010). Predisposing factors for burnout syndrome at work in emergency rooms . 131 f. Dissertation (Master's in Nursing) - Federal University of Bahia, Salvador.

3. FLECK, M.P.A. (2000). The instrument for assessing quality of life of the World Health Organization (WHOQOL - 100): characteristics and perspectives. History Public Health, 5 (1), 33-8.

4. FLECK, M.P.A. (2008). Conceptual problems in quality of life. In: Fleck, M. P. A. et al. The evaluation of quality of life guide for health professionals. New York: Guilford Press, 19-28.

5. WHOQOL GROUP. (1995). The World Health Organization quality of life assessment: position paper from the World Health Organization. Social Science and Medicine, 41, 1403-10. 
6. MARTINS, D. A. (2010). Considerations on Quality of Life at Work and Occupational Stress. In: Quality of Life: Evolution of Concepts and Practices of the XXI Century. 1st ed. Campinas, 131-139.

7. FERNANDES, J.S., et al. (2012). A relação dos aspectos profissionais na qualidade de vida dos enfermeiros das equipes Saúde da Família. Rev. esc. enferm. USP, São Paulo, 46 (2). http://www.scielo.br/scielo.php?script=sci_arttext\&pid=Soo80-62342012000200019\&lng = en\& nrm =iso. Accessed o1 July 2014.

8. LOPES, T.O., MACEDO, A.P.B. (2013). Assessment of quality of life of primary care nurses. Interscientia, João Pessoa, 1 (3), 16-27.

9. VASCONCELLOS, N.P.C., COSTA, - Val R. (2008). Evaluation of the quality of life of community health workers in Lagoa Santa - MG. Rev. APS, 11 (1) :17- 28.

10. PATRICK, D. L. (2008). The quality of life can be measured? How? In: Fleck, M. P. A. et al. The evaluation of quality of life guide for health professionals. New York: Guilford Press, 29-39.

11. MENDONÇA, P., OLIVEIRA, M.F.A. (2013). Quality of life of workers Primary Care Amparo - SP. Proceedings ...

12. URSINE, B. L., CAMPER, C.S., NUNES, E. de F.P.A. (2010). The Community Health Agent in the Family Health Strategy: an investigation of working conditions and quality of life. Revista brasileira Saúde Ocupacional, São Paulo, 35 (122), 327-339.

13. PASCHOAL, T., TAMAYO, A. (2004). Impact of work values and family-work interference in occupational stress. Psychology: Theory and Research, 21, 173-180.

14. SANTOS, F.D. et al. (2010). The stress of nurses in adult intensive care units: a literature review. SMAD, Rev. Electronics Mental Health Alcohol Drog, Ribeirão Preto, 6 (1).

15. TREVISAN, M., MENDES, I., LAWRENCE, M. (2009). Ethical aspects of managerial action by nurses. Rev Latino Americano Nursing, 10 (1), 85-89.

16. MIRANDA, A. (2008). Occupational Stress: the invisible enemy nurse. $212 \mathrm{f}$. Dissertation (Master's in Nursing) - Nursing School of Ribeirão Preto, University of São Paulo, Ribeirão Preto.

17. GONÇALVES, A. (2010). Whoqol - Before, during, after, and now. In: Quality of Life: Evolution of Concepts and Practices of the XXI Century. 1st ed. Campinas: 123-129.

18. SCHRAMM, F.R., KOTTOW, M. (2001). Principios bioéticos en salud pública: limitaciones y propuestas. Caderno Saúde Pública, Rio de Janeiro, 17(4), 949-956. 